\title{
High-temperature Oxidation of Intermetallics Based on Ti-Al-Si System
}

\author{
Anna Knaislová, Vendula Šimůnková' Pavel Novák \\ Department of Metals and Corrosion Engineering, University of Chemistry and Technology Prague. Technická 5, 16628 \\ Prague. Czech Republic. E-mail: knaisloa@vscht.cz
}

\begin{abstract}
Ti-Al-Si alloys excel with their low density and good resistance against high-temperature oxidation in comparison with so far commonly used nickel alloys. Silicon in Ti-Al-Si alloys has significant positive effect on hightemperature oxidation due to increasing adhesion of oxide layer. The TiAl20Si20 alloy was evaluated as the best alloy from tested ones, because its oxide layer protected very well the basic material and TiAl20Si20 achieved good hardness after 400 hours of annealing.
\end{abstract}

Keywords: Thermal stability, Parabolic constant, Intermetallics, Reactive sintering

\section{Introduction}

Over the past 20 years, a large research of hightemperature materials (especially intermetallics) progresses. There is a growing demand for special materials for aerospace and automotive applications. Titanium aluminides have the most importance and they are most promising materials for these applications due to their low density, good thermal stability, good oxidation resistance at $600-800{ }^{\circ} \mathrm{C}$, high specific strength at elevated temperatures and favourable ratio between mechanical properties and density [1-3]. TiAl alloys have a problem with low ductility and fracture toughness at room temperature. They also have poor resistance against oxidation at high temperature (cannot be used at temperatures above $827^{\circ} \mathrm{C}$ ), although they are containing $50 \%$ of aluminium, because rutile (TiO2) forms prior $\mathrm{A} 12 \mathrm{O} 3$ in oxide layer. Approximately $75 \%$ of the aluminium in alloy is needed to form an oxide layer at $900{ }^{\circ} \mathrm{C}[4]$.

Addition of silicon and aluminium into the titaniumbased alloys decreases the oxidation rate at temperatures below $850{ }^{\circ} \mathrm{C}$. The formation of $\mathrm{SiO}_{2}$ in the oxide layer of titanium has been described [5]. Addition of $\mathrm{Si}, \mathrm{Ni}, \mathrm{Cr}$ or $\mathrm{V}$ into $\mathrm{TiAl}$ alloys improves the high-temperature behaviour of these alloys. Silicon is the most suitable candidate for the formation of $\mathrm{Ti}_{5} \mathrm{Si}_{3}$ phase, which has significant strengthening effect and positive effect on high-temperature oxidation due to increasing adhesion of the oxide layer. Oxygen diffuses in $\mathrm{SiO}_{2}$ slower than in $\mathrm{TiO}_{2}$. Titanium nitride (TiN) is formed under the oxide layer (at the place of further oxidation). Formation of TiN results from the presence of silicon in the material (no $\mathrm{TiN}$ has been observed in Ti-Al alloys). The reason, why TiN is formed, is that silicon reduces the solubility and diffusion rate of nitrogen in titanium alloys [6-9].

Materials based on the Ti-Al-Si alloys consist from two types of intermetallic phases. The titanium silicides in matrix of the titanium aluminides, both of which have excellent resistivity against high-temperature oxidation. In particular, $\mathrm{Ti}_{5} \mathrm{Si}_{3}$ has an even better resistance against high-temperature oxidation than TiAl $[10,11]$.

The aim of this work is the description of resistance against oxidation of Ti-Al-Si alloys prepared by reactive sintering and compaction by Spark Plasma Sintering and evaluation of thermal stability of the alloys at $1000{ }^{\circ} \mathrm{C}$, which exceeds temperature limit of application alloys based on Ti-Al system.

\section{Experiment}

Ti-Al-Si alloys were prepared by powder metallurgy, powder of titanium, silicon and powder of AlSi30 alloy, which was prepared by mechanical machining, were mixed. Powders were compressed by the LabTest 5.250SP1VM machine into the tablets. The pre-pressed powders were sealed into evacuated quartz glass ampoules to provide protection against oxidation during reactive sintering $\left(900{ }^{\circ} \mathrm{C}, 30\right.$ minutes in preheated furnace). The reactive sintered samples were milled in a VM4 laboratory mill. Milled powders were then compacted by Spark Plasma Sintering using temperature of $1200{ }^{\circ} \mathrm{C}$ for 15 minutes with a heating rate of $100{ }^{\circ} \mathrm{C} / \mathrm{min}$. The pressure was set at $48 \mathrm{MPa}$ and the sintering was carried out in continuous mode. The samples were then unloaded to $3 \mathrm{kN}$ and subsequently cooled at a rate not exceeding $50^{\circ} \mathrm{C} / \mathrm{min}$.

The isothermal tests were carried out in air in electric resistant furnace at $1000{ }^{\circ} \mathrm{C}$. The samples were removed sequentially for 100 hours, 200, 300 and 400 hours. The samples were cooled spontaneously in the air. The cooled samples were weighed and then the metallographic cut was made. The samples were polished, etched and observed by light and electron microscopy. The area of the exposed surfaces was determined by image analysis using program Atlas.

On the Future-Tech FM-700, microhardness with a load of $100 \mathrm{~g}$ (HV 0.1) was measured, ten imprints were performed and the averaged values were averaged.

\section{Results and discussion}

Isothermal tests were carried out in air at $1000{ }^{\circ} \mathrm{C}$. The alloys were kept in the furnace continuously for 100 hours, 200, 300 and 400 hours. The increase in weight in relation to the annealing time is shown on Fig. 1. The dashed line indicates the weight dependence of the alloy, including the scalled-off oxides, on the annealing time. The full line curves indicate the weight of the alloy depending on the annealing time. TiAl10Si20 and TiAl15Si15 are characterized by a strong oxide layer with good adhesion. TiAl20Si20 alloy has a weaker oxide layer with worse adhesion than other alloys. In the case 
of alloys containing smaller amount of silicon (TiAl15Si15 and TiAl20Si20), the adhesion of the oxide layer was significantly increased compared to the cyclic tests [12]. The resulting oxide layers are brittle and porous with frequent cracks for the alloys.



Fig. 1 Dependency of mass gain of the Ti-Al-Si alloys (sample and sample + scaled-off oxides) at the time of isothermal oxidation

The growth of the oxide layer can be controlled by diffusion (parabolic dependence) or by chemical reaction (linear dependence). From the values of parabolic constants (Table 1), the growth of the oxide layer of TiAl10Si20 and TiAl15Si15 is controlled by chemical reaction because the weight gains curves at the annealing time showed linear dependence (Fig. 2). The resulting oxide layers of these alloys are very porous with frequent cracks. The formed layers do not have a protective effect and after 400 hours the basic material has completely oxidized. In the case of TiAl20Si20 alloy, the diffusion mechanism of the growth of the oxide layer can be assumed
(Tab. 1, Fig. 2).

The mechanism of formation of the oxide layers can also be read using a plot of the depencence of growth of Ti-Al-Si alloy oxide layers at the annealing time (Fig. 2). In the case of TiAl10Si20 and TiAl15Si15 alloys, we can see an almost linear increase in the thickness of the oxide layer. After 400 hours, it was no longer possible to recognize the boundary between the layer and the basic material. In the case of TiAl20Si20 alloy, it can be observed that the oxide layer stops to grow after 200 hours of annealing. The layer then protected the basic material well.

Tab. 1 Kinetics of the Ti-Al-Si alloy oxide growth in isothermal oxidation

linear constant

$k l$

TiAl10Si20

TiAl15Si15 parabolic constant

$\left[\mathrm{g} \cdot \mathrm{m}^{-2} \cdot \mathrm{h}^{-1}\right]$

\begin{tabular}{ccccc}
\hline$k l 100$ & 4.446 & 4.842 & $k p 100$ & $2.7 \cdot 10^{2}$ \\
$k l 200$ & 4.984 & 5.681 & $k p 200$ & $1.7 \cdot 10^{3}$ \\
$k l 300$ & - & - & $k p 300$ & $1.8 \cdot 10^{3}$ \\
$k l 400$ & 4.862 & 4.803 & $k p 400$ & $4.9 \cdot 10^{3}$
\end{tabular}

TiAl20Si20 




Fig. 2 Dependency of growth of Ti-Al-Si alloy oxide layers at the time of isothermal oxidation

The TiAl10Si20 and TiAl15Si15 are characterized by deteriorated thermal stability due to annealing at $1000{ }^{\circ} \mathrm{C}$. On the microstructure of these alloys, we can see extensive areas of pores and cracks. The amount of basic material gradually decreased because of the increase of the oxide layers thickness and after 400 hours, it had already completely oxidized. The deterioratiton of the mechanical properties can be observed in the drop of hardness HV 0.1 (Fig. 3). The thermal stability of the TiAl20Si20 alloy was very good compared to other alloys. The material under the oxide layer was well protected and did not contain any major defects (Fig. 4). TiAl20Si20 alloy achieved good hardness after 400 hours of annealing at the temperature of $1000{ }^{\circ} \mathrm{C}$ (Fig. 3).

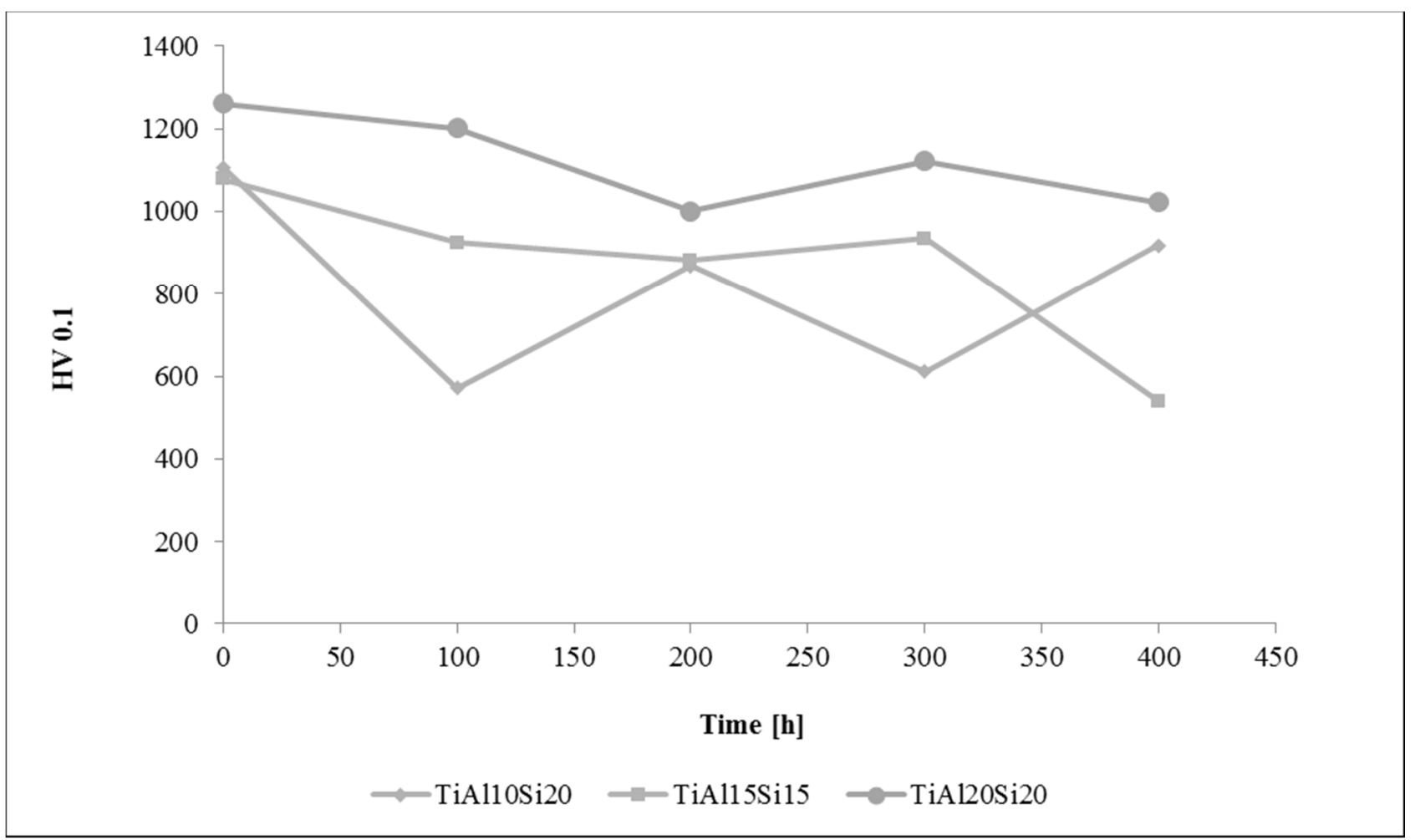

Fig. 3 Hardness of the Ti-Al-Si alloys depending of the time of isothermal oxidation 

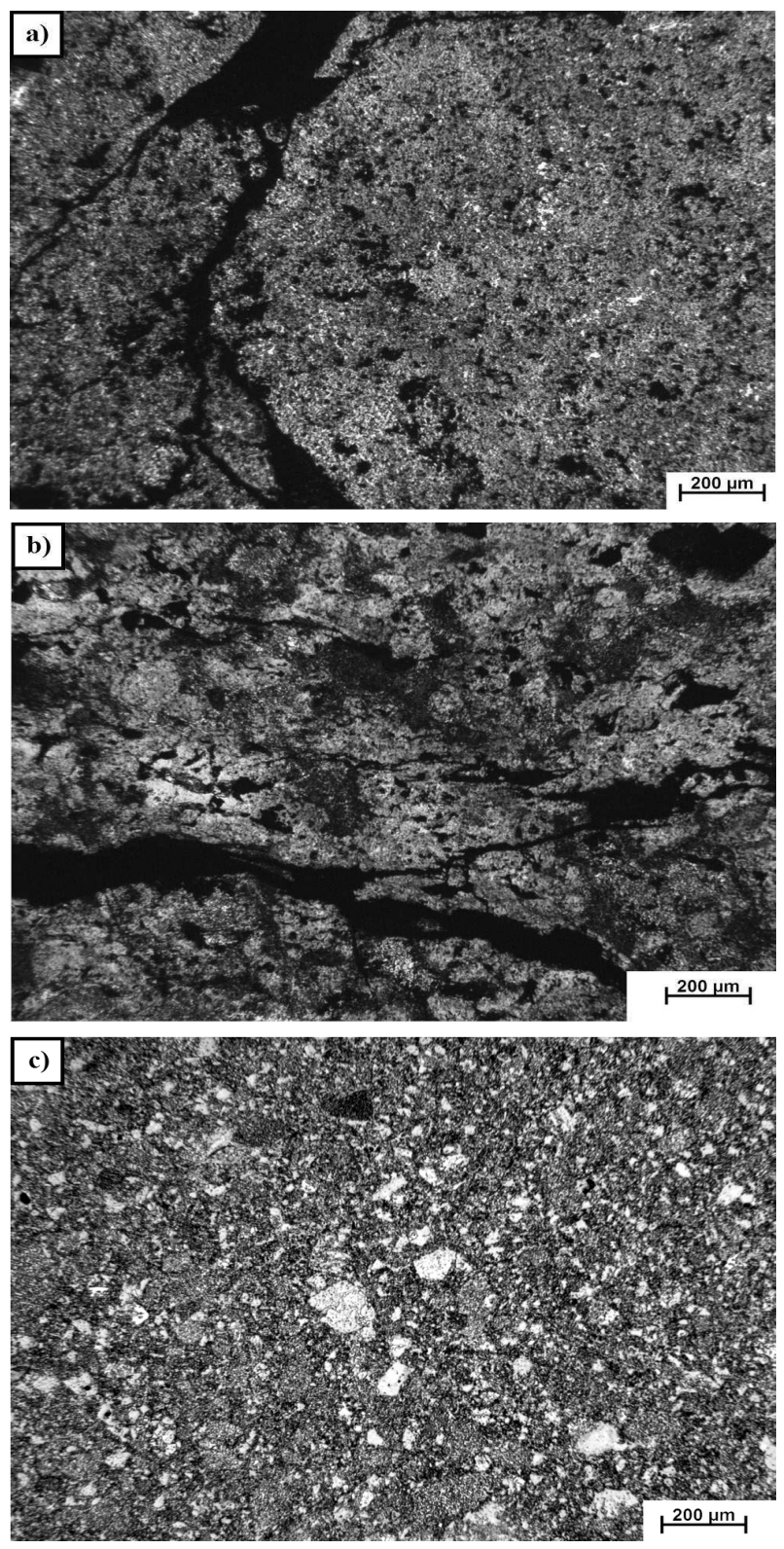

Fig. 4 Microstructure of TiAl10Si20 (a), TiAl15Si15 (b) and TiAl20Si20 (c) alloys after 100 hours of annealing

\section{Conclusion}

Isothermal oxidation tests of the Ti-Al-Si alloys were performed. The annealing temperature was chosen for a higher temperature $\left(1000{ }^{\circ} \mathrm{C}\right)$ than the reported maximal application temperature $\left(800^{\circ} \mathrm{C}\right)$ of Ti-Al alloys. TiAl20Si20 was evaluated as the best alloy of the tested ones, the layer protected the basic material against the further oxidation. On the TiA210Si20 alloy, the diffusion of oxide layer with very good adhesion has been demonstrated. TiAl20Si20 alloy achieved good hardness after 400 hours of annealing at the temperature of $1000^{\circ} \mathrm{C}$.

\section{Acknowledgement}

This research was financially supported by Czech Science Foundation, project No. P108/12/G043 and from specific university research MSMT No 20SVV/2017.

\section{References}

[1] NOVÁK, P., PRŮŠA, F., ŠERÁK, J., VOJTĚCH, D.,MICHALCOVÁ, A. (2009). Oxidation resistance and thermal stability of Ti-Al-Si alloys produced by reactive sintering. In: Metal, Vol. No.

[2] GUAN, Z. Q., PFULLMANN, T., OEHRING, M.,BORMANN, R. (1997). Phase formation during ball milling and subsequent thermal decomposition of Ti-Al-Si powder blends. In: Journal of Alloys and Compounds, Vol. 252, No. 1-2, pp. 245-251.

[3] NOVÁK, P., VOJTĚCH, D., ŠERÁK, J., KUBÁSEK, J., PRŮŠA, F., KNOTEK, V., MICHALCOVÁ, A.,NOVÁK, M. (2009). Synthesis of Intermediary Phases in Ti-Al-Si System by Reactive Sintering. In: Chemické listy, Vol. 103, No. 1022-1026.

[4] SHIDA, Y.,ANADA, H. (1993). The influence of ternary element addition on the oxidation behaviour of TiAl intermetallic compound in high temperature air. In: Corrosion Science, Vol. 35, No. 5, pp. 945-953.

[5] NOVÁK, P. (2012). Př́prava, vlastnosti a použití intermetalických sloučenin. In: Chemické listy, Vol. 106, No. 884-889.

[6] STOLOFF, N. S., LIU, C. T.,DEEVI, S. C. (2000). Emerging applications of intermetallics. In: Intermetallics, Vol. 8, No. 9-11, pp. 1313-1320.

[7] NESPER, R. (1996). Intermetallics. Von G. Sauthoff. VCH Verlagsgesellschaft, Weinheim, 1995. 165 S., geb. 128.00 DM. - ISBN 3-527-29320-5. In: Angewandte Chemie, Vol. 108, No. 6, pp. 726727.

[8] YEH, C. L., WANG, H. J.,CHEN, W. H. (2008). A comparative study on combustion synthesis of Ti-Si compounds. In: Journal of Alloys and Compounds, Vol. 450, No. 1-2, pp. 200-207.

[9] SHI, D., WEN, B., MELNIK, R., YAO, S.,LI, T. (2009). First-principles studies of Al-Ni intermetallic compounds. In: Journal of Solid State Chemistry, Vol. 182, No. 10, pp. 2664-2669.

[10] MUNIR, Z. A., ANSELMI-TAMBURINI, U.,OHYANAGI, M. (2006). The effect of electric field and pressure on the synthesis and consolidation of materials: A review of the spark plasma sintering method. In: Journal of Materials Science, Vol. 41, No. 3, pp. 763-777.

[11] STOLOFF, N. S.,SIKKA, V. K. (1996). Physical metallurgy and processing of intermetallic compounds. Chapman \& Hall.

[12] KNAISLOVÁ, A., ŠIMŮNKOVÁ, V., NOVÁK, P.,PRŮŠA, F. (2017). High-temperature behaviour of Ti-Al-Si alloys prepared by Spark Plasma Sintering. In: Manufacturing Technology, Vol. 17, No. 5, pp. 733-738. 